\title{
TRAJETÓRIA DAS POLÍTICAS DE FORMAÇÃO CONTINUADA DE PROFESSORES NO ÂMBITO DA SECRETARIA DA EDUCAÇÃO DO ESTADO DE SÃO PAULO
}

http://dx.doi.org/10.5902/2318133867223

\author{
Nonato Assis de Miranda ${ }^{1}$ \\ André dos Anjos Cangueiro Silva² \\ Ana Silvia Moço Aparício ${ }^{3}$ \\ Leliane Aparecida Gliosce Moreira ${ }^{4}$
}

\begin{abstract}
Resumo
A formação continuada de professores tem se constituído em projeto de governos com foco na melhoria da qualidade da educação. Esse assunto não é novo, mas nas últimas décadas tem ganhado destaque no âmbito das políticas públicas de educação. Por meio de exploração documental e bibliográfica, objetivou-se analisar a trajetória das políticas de formação continuada de professores da Secretaria da Educação de São Paulo - Seduc/SP. As análises mostram que essas ações estão inseridas em programas de governo com ênfase nas políticas educacionais e curriculares da Seduc/SP. Conclui-se que, em razão da racionalidade, da eficiência, da cobrança por resultados, as políticas de formação continuada de professores da Seduc/SP não têm inovado.

Palavras-chave: políticas educacionais; formação continuada de professores; Seduc/SP.
\end{abstract}

\section{TRAJECTORY OF CONTINUING TEACHER EDUCATION POLICIES WITHIN THE SCOPE OF THE SAO PAULO STATE EDUCATION DEPARTMENT}

\begin{abstract}
The teachers' continuing in-school training has been constituted in government projects focused on improving the education quality. This subject is not new, but in recent decades, it has gained prominence in the scope of public education policies. Through documentary and bibliographic exploration, this article aimed to analyze the trajectory of the teacher continuing in-school training policies of the São Paulo Education Department - Seduc/SP. The analyzes show that these actions are inserted in government projects and programs with an emphasis on Seduc/SP's educational and curricular policies. It concludes that, due to rationality, efficiency, demand for results Seduc/SP's teacher continuing in-school training policies have not innovated.

Keywords: educational policies; teacher continuing training; Seduc/SP.
\end{abstract}

\footnotetext{
${ }^{1}$ Universidade Municipal de São Caetano do Sul, Brasil. E-mail: mirandanonato@uol.com.br.

2 Universidade Paulista/Universidade Municipal de São Caetano do Sul, Brasil. E-mail: andre anjos@yahoo.com.br.

${ }^{3}$ Universidade Municipal de São Caetano do Sul, Brasil. E-mail: anaparicio@uol.com.br.

${ }^{4}$ Universidade Paulista, Brasil. E-mail: leliane.moreira@docente.unip.br.
}

Regae: Rev. Gest. Aval. Educ. $\quad$ Santa Maria $\quad$ v. 10 n. 19

n. 19 e67223, p. 1-16

2021 


\section{Introdução}

A formação continuada de professores tem sido defendida como algo Andispensável à melhoria da educação, tanto no Brasil, quanto em outras nações. Essa discussão não é recente, pois já faz uns quarenta anos que ela tem feito parte da agenda das políticas públicas de educação, mas nesta última década ganhou um destaque ainda maior nesse cenário.

Tem sido comum observarmos governos e gestores públicos implementando políticas educacionais a partir das quais a formação continuada de professores no interior da escola passou a ser considerada, na perspectiva deles, a essência de ações que buscam a melhoria da qualidade da educação. A Secretaria da Educação do Estado de São Paulo - Seduc/SP -, por exemplo, não foge a essa regra tendo implantado um conjunto de ações, programas e políticas educacionais focalizando a busca da melhoria da qualidade da educação. Em geral essas ações visam ao desenvolvimento profissional dos seus professores com foco na "implementação efetiva do currículo por meio do aperfeiçoamento das práticas pedagógicas do professor, visando à melhoria da aprendizagem dos estudantes" (São Paulo, 2021, p. 1).

Essa perspectiva em especifico está pautada no Projeto de Assistência ao Currículo - PAC -, a partir do qual a Seduc/SP nomeia um professor que terá a função de apoiar outros colegas de sua área de atuação

na elaboração de planos de aula, analisando-os e oferecendo devolutivas formativas individualizadas, com sugestões de metodologias e didáticas para favorecer o desenvolvimento das competências e habilidades de cada componente curricular ou área do conhecimento. (São Paulo, 2021, p. 1)

A formação continuada de professores tem feito parte das políticas públicas de educação da Seduc/SP. Além disso, a exemplo do que ocorre em âmbito nacional, no Estado de São Paulo a formação continuada desses profissionais tem sido uma ação pautada em orientações político-ideológicas vigentes o que, a nosso ver, não poderia ser diferente, pois compreendemos que as políticas públicas de educação não estão alheias a outras políticas e programas que orientam a gestão pública.

Em face ao exposto, buscamos com este texto descrever e analisar a trajetória das políticas púbicas de formação continuada de professores da Seduc/SP nas últimas décadas.

\section{Políticas de formação continuada da Seduc/SP nos anos de 1980 e 1990}

Lippi e Neira (2013) dividem as políticas de formação continuada de professores da Seduc/SP em dois momentos. O primeiro, compreendido entre 1983 e 1994, é caracterizado pela pulverização de tentativas de romper com os paradigmas impostos pelos governos ditatoriais de períodos anteriores. O segundo, por sua vez, entre $1995 \mathrm{e}$ 2006, é marcado pela proposição de políticas formativas alinhadas ao ideário neoliberal. Esses autores são bastante críticos às políticas de formação de professores da Seduc/SP, conforme pode ser constado neste excerto:

Os resultados de nossas análises contrariam qualquer discurso de mudança de rumos ou direções. Inversamente, sobram razões para afirmar a existência de um continuum nas ações formativas. As evidências indicam 
que a centralização das decisões, as iniciativas episódicas, a ausência de canais de diálogo com os profissionais da educação e a falta de criticidade com relação à tarefa educacional, há muito permeiam a política estadual de formação de professores. (Lippi; Neira, 2013, p. 78)

Essa análise denota o entendimento que esses autores têm sobre o assunto que, se por um lado, pode nos parecer um tanto rígida, por outro deixa pistas de que o modelo de formação continuada de professores adotado nessa rede de ensino mostra-se superado e em desacordo com as demandas vigentes do século 21, conforme tem sido apontado em estudos e pesquisas que discutem a temática (Kramer, 1989; André, 2002; Imbernón, 2009; 2010).

Com relação às políticas de formação continuada de professores em si, nosso primeiro destaque recai sobre o Projeto Ipê criado em 1984. Seu lançamento aconteceu em paralelo à implantação do ciclo básico com o intuito de combater a evasão, repetência e fracasso escolar. A proposição desse curso tornou-se necessária porque o ciclo básico se constituiu não somente num ato administrativo, mas também uma mudança de concepção do processo de alfabetização.

O Projeto Ipê consistia numa ação formativa a distância, que buscou atingir toda a rede por meio da transmissão de programas de rádio e TV, acompanhados da discussão de textos de referência. Apesar de ser uma iniciativa inovadora para época em face de sua metodologia, o projeto foi objeto de muitas críticas. Duran, Alves e Palma Filho (2005), por exemplo, consideram que a despeito de o projeto ter alcançado grandes contingentes de professores em curto período de tempo, constituiu-se num plano superficial que intentou tão somente divulgar ideias e propostas. Os programas buscavam enfatizar aspectos metodológicos da alfabetização com o propósito de combater "o predomínio das cartilhas e das teorias da prontidão" (Lippi; Neira, 2013, p. 79).

Nesse mesmo período teve início um debate acerca da construção de propostas curriculares com vistas a substituir os guias curriculares criados nos anos de 1970. Assim, a Coordenadoria de Estudos e Normas Pedagógicas - Cenp -, órgão da Seduc/SP responsável pelas questões referentes aos currículos, à época, organizou ações que envolviam a participação docente, discussões e debates entre professores, especialistas de universidades que assessoravam a Seduc/SP e representantes sindicais (Palma Filho, 2003).

O método de formação adotado pela Cenp foi de cursos de curta duração ministrados em parceria com universidade públicas e privadas. Esse projeto foi considerado inadequado porque representou uma

postura exatamente contrária ao processo de construção dos documentos, pois a divisão regional da formação e a falta de articulação entre as instituições participantes desencadeou no oferecimento de cursos, treinamentos e orientações técnicas pontuais. (Lippi; Neira, 2013, p. 79)

De 1987 a 1997, período da gestão do governador Orestes Quércia, a formação continuada de professores não contou com nenhuma ação relevante. O que se constata é que houve apenas cursos de capacitação estanques e desarticulados com as 
necessidades das escolas. Os projetos propostos ignoravam a experiência dos professores dessa rede de ensino, assim como desprezavam suas condições objetivas de trabalho (Fusari, 1988).

Complementarmente, no âmbito local, mais precisamente, nas Delegacias de Ensino ${ }^{5}$, foram criadas as Oficinas Pedagógicas, atual Núcleo Pedagógico, que passaram a desenvolver ações formativas por professores de diferentes áreas que exerciam a função de assistente técnico pedagógico que, hoje, são chamados de Professor Coordenador do Núcleo pedagógico, mas com funções bastante similares.

A gestão do governador Luiz Antônio Fleury Filho (1991-1995), também não trouxe grandes mudanças, mas representou um avanço em relação ao governo anterior acerca da formação continuada de professores. Nesse período a Cenp, a Fundação para o Desenvolvimento da Educação - FDE - e o Departamento de Recursos Humanos - Drhu passaram a compartilhar a responsabilidade pelos programas formativos da Seduc/SP.

A Cenp continuou com o mesmo método que vinha adotando em gestões anteriores, que era o da oferta de cursos de aperfeiçoamento para professores, por meio de convênios com as universidades estaduais paulistas, assim como instituições de notório reconhecimento. O Projeto Ipê, que ficou em segundo plano no governo Quércia, foi retomado para oferecer materiais de suporte aos professores com vistas à implementar a proposta curricular, assim como para subsidiar na divulgação do Projeto Vídeo-Escola, organizado pelas Fundações Roberto Marinho e pelo Banco do Brasil (Lippi; Neira, 2013). A FDE, por sua vez, assumiu uma parte significativa da formação de professores nesse período, promovendo cursos, seminários, encontros, oficinas, visitas técnicas e pesquisas. Já o Drhu promoveu cursos e orientações técnicas de caráter pontual (Utsumi, 1995; Lippi, Neira, 2013).

Na perspectiva de Lippi e Neira (2013), esse primeiro período foi marcado por diversas tentativas de se implementar uma política de formação continuada para professores da Seduc/SP. Não obstante, a descontinuidade e fragmentação das ações e programas acabaram impedindo o desenvolvimento de projetos mais duradouros com foco no desenvolvimento profissional (Imbernón, 2010), numa perspectiva de políticas públicas de educação (Gatti et al., 2019). Todavia, não podemos negar que apesar da fragmentação e descontinuidade dessas ações, elas fizeram parte das políticas públicas de educação do governo estadual paulista no período em questão (1983 a 1994).

O segundo momento proposto por Lippi e Neira (2013), no que tange às políticas públicas de formação continuada de professores da Seduc/SP, envolve o período de 1995 a 2006. Em âmbito nacional, nos anos 1990, notadamente, na gestão do presidente Fernando Henrique Cardoso, as políticas públicas em geral, o que inclui as educacionais, foram

orientadas por meio, entre outros processos, da reforma de Estado que [...] engendra alterações substantivas nos padrões de intervenção estatal, redirecionando mecanismos e formas de gestão e, consequentemente, as políticas públicas e, particularmente, as políticas educacionais em sintonia com os organismos multilaterais. (Dourado, 2002, p. 241)

${ }^{5}$ As Delegacias de Ensino foram substituídas pelas atuais Diretorias Regionais de Ensino.

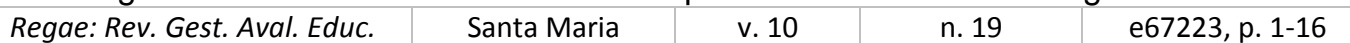
2021 
Como consequência, essas ações reverberaram na arena educacional expressandose principalmente num processo que culminou na aprovação da Lei de Diretrizes e Bases de 1996. Esse fato se, por um lado pode ter representado um avanço no que tange às políticas regulatórias de educação, por outro recebeu muitas críticas porque o projeto de lei aprovado não foi o original. Essa medida acabou "negligenciando parte das bandeiras encaminhadas pela sociedade civil, especialmente o Fórum Nacional em Defesa da Escola Pública" (Dourado, 2002, p. 241).

Esse modelo de gestão pública foi adotado pela maioria dos Estados, notadamente, os administrados por governadores do Partido da Social Democracia Brasileira - PSDB como é o caso de São Paulo com Mário Covas (1995-2001). É sabido que nesse governo houve o fortalecimento do processo descentralização, mas mesmo diante de uma perspectiva democrática, a vertente gerencial tornou-se a tônica dessa gestão. Com isso, alguns conceitos como os de descentralização e participação popular, inerentes às sociedades democráticas, foram substituídos por descentralização e produtividade "instaurando o período da eficiência pautada pela otimização dos recursos financeiros" (Lippi; Neira, 2013, p. 83-84).

Esse modelo gerencial adotado por São Paulo chegou na educação, sendo que a descentralização acabou tornando-se muito mais um processo de desconcentração de serviços administrativos. Tal prática se efetivou, por exemplo, por meio da alteração na natureza jurídica das associações de pais de mestres que, a partir de então, passaram a receber recursos públicos para serviços essenciais e, em um dado momento, até mesmo para contratação de pessoal.

Nessa gestão a Seduc/SP lançou o programa intitulado $A$ escola de cara nova que, dentre outros propósitos, buscava modernizar essa rede de ensino com o intuito de adequá-las às exigências da globalização econômica, assim como de organismos internacionais (Gatti, 2008). Como havia a necessidade de racionalizar recursos os órgãos intermediários foram extintos e instituído o módulo de pessoal a partir do qual ficou estabelecido desde então a quantidade de servidores em face do número de escolas atendidas (Adrião, 2006; Lippi; Neira, 2013).

A formação continuada de professores ficou a cargo das Oficinas Pedagógicas que assumiram a responsabilidade de acompanhar a formação de todos os professores das Diretorias de Ensino que atuavam com as mesmas disciplinas. A racionalização foi tamanha que, de 1995 a 1998, esse projeto alcançou 864 escolas da Seduc/SP em âmbito estadual (Lippi; Neira, 2013). Tal situação foi possível em face do aumento da relação professor/aluno e da implementação da correção de fluxo que fez parte das políticas educacionais dessa época (Adrião, 2006).

Mas a ação formativa de maior destaque dessa época foi a criação, no período de janeiro de 1995 a dezembro de 1996, do Programa de Educação Continuada - PEC - para atender aos professores da Seduc/SP. Como a Cenp teve uma redução drástica do quadro de pessoal, para dar conta de seus propósitos formativos terceirizou serviços por meio da contratação de empresas e organizações não governamentais que passaram a oferecer-lhe assessoria pedagógica, notadamente, o Centro de Estudos e Pesquisas em Educação, Cultura e Ação Comunitária - Cenpec. Esse projeto foi financiado com 
recursos recebidos por meio de empréstimos do Banco Mundial que passou a ter forte influência nas políticas educacionais de vários países incluindo, portanto, o Brasil e suas unidades federadas que foram beneficiadas com tais recursos (Cortina, 2000 apud Lippi; Neira, 2013; Gatti, 2008).

Em face das orientações políticas vigentes à época, a Seduc/SP conseguiu atender as prioridades das Diretorias de Ensino abrindo espaço para que as universidades e agências capacitadoras ${ }^{6}$ desenvolvessem seus projetos em 19 polos espalhados por todo o Estado de São Paulo. Esse projeto, em face de sua metodologia, possibilitou inúmeras iniciativas, assim como o atendimento de cerca de 90 mil servidores no período (Gatti, 2008). Dentre outros aspectos, talvez o maior destaque desse projeto tenha sido a possibilidade de cada Diretoria de Ensino poder escolher entre os "cursos contratados para sua região, aqueles que se aproximavam das necessidades identificadas pelas escolas" (Lippi; Neira, 2013, p. 85).

\section{Políticas de formação continuada da Seduc/SP nos anos 2000}

A gestão de Geraldo Alckmin (2001-2006) não inovou no que tange à formação continuada de professores prevalecendo a oferta de cursos voltados ao atendimento de necessidades da Seduc/SP por meio de convênios com ONG e universidades, por intermédio da Cenp. Dentre as diversas ações formativas desse governo, embora nem todas tenham foco na docência, merecem destaquem os seguintes projetos: Progestão ${ }^{7}$, Teia do Saber, PEC-Formação Universitária, Ensino Médio em Rede, Bolsa Mestrado, Letra e Vida e Lien'chi (Lippi; Neira, 2013; Monteiro et al., 2014).

Para análise desses programas, além dos documentos oficiais, tomamos como base, também as contribuições de Lippi e Neira (2013), assim como as de Monteiro et al. (2014).

O Teia do Saber foi um programa que buscou formar professores do ensino fundamental e do ensino médio com o propósito de utilizar metodologias inovadoras e práticas de avaliação como instrumento que possibilitasse o redirecionamento das ações, assim como que promovesse um ensino baseado no desenvolvimento de competências (São Paulo, 2007). Para tanto, contou com a realização de convênio firmados entre a Seduc/SP e instituições de ensino superior.

O Ensino Médio em Rede foi um programa destinado a vários profissionais da Seduc/SP, dentre eles, os Professores da Educação Básica II - PEB II - que atuavam no ensino médio. Num primeiro momento (2004 e 2005) esse curso centrou-se no desenvolvimento de conteúdos voltados à contextualização da proposta de formação e para a discussão das múltiplas representações dos atores envolvidos na prática educativa. Em sua segunda etapa, versou sobre o desenvolvimento curricular das quatro áreas de conhecimento do ensino médio.

6 Fizeram parte do PEC: USP, Unesp, Unicamp, PUCSP, UMC, Instituto Paulo Freire, Universidade de Taubaté, Ufscar, Cenpec, Cooperativa Técnico-Educacional, Escola da Vila (Gatti, 2008).

7 O Progestão embora seja um programa de formação continuada, seu foco foram os gestores escolares. Esse curso foi uma iniciativa do Conselho Nacional de Secretários de Educação e intercalou atividades presenciais e a distância. 
O Programa Letra e Vida foi um curso oferecido pela Seduc/SP a partir de 2003 que teve foco na melhoria da qualitativa e quantitativa da alfabetização no sistema público de ensino. Dentre os profissionais que beneficiaram com esse curso estão supervisores de ensino e os professores coordenadores da oficina pedagógica que ficaram responsáveis pelo desenvolvimento da formação continuada de professores alfabetizadores.

A Bolsa Mestrado e Bolsa Doutorado foi um programa que incentivou a formação continuada de professores na Seduc/SP criando oportunidades para professores e integrantes do suporte pedagógico do quadro do magistério desenvolver estudos e pesquisas em cursos de stricto sensu na área da educação ou da licenciatura do profissional.

O Lien Ch'i foi um projeto iniciado em 2003 que contou com a parceria da Associação de Medicina Chinesa cuja finalidade era capacitar os professores para ensinar a técnica corporal. Esse projeto destinava-se aos professores de Educação Física num primeiro momento, mas depois voltou-se também para outros profissionais da educação.

O pec-formação universitária foi criado, principalmente, mas não exclusivamente, para atender as exigências impostas pela LDB de 1996 no que tange à formação de professores em nível superior. Sua concepção seguiu um modelo já consolidado na Seduc/SP que eram os convênios que, nesse caso, foram firmados com a PUCSP, USP e Unesp associando as modalidades presencial e a distância.

Conforme sinalizam Lippi e Neira (2013, p. 87), de 1995 a 2006, "a política de formação contínua da SEE/SP abrangeu cursos estanques, fragmentados e desarticulados, o que dificulta qualquer análise coletiva sobre a complexidade do contexto escolar." Todavia, nosso entendimento é que a despeito de ter havido muitos cursos, merecem destaque alguns programas, como é o caso do PEC-Formação Universitária que atendeu a um quantitativo de 2.400 professores que, por sua vez, o avaliaram positivamente permitindo com que tal ação servisse de base para a Seduc/SP traçar diretrizes futuras acerca da formação continuada de professores (Krasilchik; Nicolau; Cury, 2008). Destacamos, ainda o programa Bolsa Mestrado, que incentivou a formação continuada não somente de professores, mas também de profissionais do magistério como diretores, supervisores de ensino, dentre outros (Monteiro et al., 2014) qualificando o banco de profissionais da Seduc/SP em nível de pós-graduação stricto sensu.

$\mathrm{Na}$ gestão do governador José Serra (2007-2010), as políticas de formação continuadas de professores, no âmbito da SEDUC/SP, ganham força com criação da Efape. Isso ocorreu porque, dentre outras possiblidades, as atividades propostas pela Escola de Formação e Aperfeiçoamento dos Profissionais da Educação do Estado de São Paulo - Efape -, à época, Escola de Formação e Aperfeiçoamento dos Professores do Estado de São Paulo - Efap -, associam as modalidades presencial e a distância. Ademais, as atividades presenciais que, em geral, envolveram a prática pedagógica poderiam ser realizadas nas escolas da Seduc/SP o que acabaria favorecendo ao professor cursista. Outro aspecto que favoreceu o incremento da formação continuada de professores na Seduc/SP foi o fato de que o mesmo decreto que a criou a Efap asseverou uma prática já consolidada nessa rede de ensino que é a possibilidade de firmar convênios com universidades públicas e privadas para formar seus professores.

Nessa perspectiva foi criado o Programa Rede São Paulo de Formação Docente Redefor - por meio do decreto n. 55.650, de 29 de março de 2010, instituído no âmbito da

\begin{tabular}{|l|l|l|l|l|l|}
\hline Regae: Rev. Gest. Aval. Educ. & Santa Maria & v. 10 & n. 19 & e67223, p. 1-16 & 2021 \\
\hline
\end{tabular}


Efape. Em conformidade com o artigo $2^{\circ}$ desse decreto o Redefor teve como objetivo a "formação de até 30.000 (trinta mil) profissionais, em nível de especialização, ao longo dos exercícios de 2010 a 2012, em cursos com 12 (doze) a 14 (quatorze) meses de duração, com início no segundo semestre do ano corrente" (São Paulo, 2010, p. 1).

Consta do mesmo decreto que,

para a implementação e desenvolvimento do Programa Redefor, fica o Secretário da Educação autorizado a representar o Estado na celebração de convênios com a Universidade São Paulo - USP, a Universidade Estadual de Campinas - Unicamp e a Universidade Estadual Paulista "Júlio de Mesquita Filho" - Unesp, inclusive para fins de divisão dos cursos de formação de professores entre essas instituições. (São Paulo, 2010, p. 1)

O Redefor teve como foco o aperfeiçoamento profissional e a formação continuada de professores e gestores, em duas edições (2010 e 2011), mas o convênio foi renovado em 2013 quando foram atendidos os professores da educação especial. Em face ao número de vagas ofertadas e as metodologias adotadas, esse curso teve uma abrangência quantitativa grande, pois contemplou os professores de todas os componentes curriculares.

O segundo governo de Geraldo José Rodrigues Alckmin Filho (2011-2014), também não trouxe muitas novidades em relação aos governos anteriores no que tange à formação continuada de professores. Silva (2015) ao analisar o plano plurianual - PPA deste governo constatou que havia dois programas destinados à formação de professores: Programa Gestão Pedagógica da Educação Básica e Formação Continuada dos Profissionais da Educação. No seu conjunto, esse programa

objetiva desenvolver as competências e valorizar os profissionais da educação, garantindo a melhoria da qualidade da educação e a viabilização do trabalho pedagógico no uso de metodologias voltadas para práticas inovadoras, adotar práticas de avaliação, como instrumentos de acompanhamento do trabalho docente e do percurso do aluno, seus avanços e dificuldades, para redirecionar as ações pedagógicas. (Silva, 2015, p. 122)

No âmbito deste programa de formação continuada dos profissionais da educação a Seduc/SP criou o Melhor Gestão, Melhor Ensino - MGME. É oportuno destacar que de modo mais efetivo, na perspectiva das políticas educacionais, todas essas ações estão inseridas no programa Educação: Compromisso de São Paulo, cujo objetivo é, segunda a Seduc/SP, transformar a educação paulista numa das melhores do mundo até 2030, por intermédio de um pacto com a sociedade (São Paulo, 2011). Todavia, Rodrigues (2020, p. 22) pondera que, "ao contrário do que se anuncia como 'pacto com a sociedade', o único setor da chamada 'sociedade civil' que compõe o Conselho do Programa é o setor empresarial" (p. 22). A despeito dessa análise, para atingir esse objetivo, o governo do Estado estabeleceu cinco pilares com o foco na qualidade da educação paulista: valorização do capital humano; gestão pedagógica; educação integral; gestão organizacional e financeira e mobilização da sociedade.

De certo modo, a valorização do capital humano, para além das questões salariais, estão, também na formação continuada e no desenvolvimento profissional docente. $O$ 
MGME foi uma ação que fez parte deste projeto cujo início deu-se em 2013, prolongandose por três anos, pois a terceira edição ocorreu em 2016 e teve como foco a formação de formadores de gestão, assim como professores de Língua Portuguesa, Matemática e Ciências. Esse curso foi instituído pela resolução SE-22, de 18 de abril de 2013, da Seduc/SP e teve como objetivo principal incentivar a formação continuada de educadores dessa rede de ensino, assegurando-lhes atualização e aperfeiçoamento e, consequentemente, melhor desempenho profissional (São Paulo, 2013).

Outro programa de formação continuada docente que, apesar de não ter sido criado pelo Governo Alckmin, mas que teve continuidade em seu mandato foi o Curso específico de formação destinado aos ingressantes aprovados no concurso público para provimento de cargo de professores da educação básica - PEB I e PEB II. Em razão do tempo de duração, as primeiras turmas desse curso foram finalizadas em 2011, quando cerca de 14.000 professores foram certificados (Efape, 2011).

No ano de 2013 a Seduc/SP, em atendimento ao artigo $1^{\text {o }}$ da lei complementar $n$. 1.207 , de 5 de julho de 2013, criou um novo curso, mas desta vez para atender aos professores da educação básica I: PEB I. Essa lei dispõe sobre os concursos públicos regionalizados para os integrantes do quadro do magistério dessa rede de ensino. Assim, além normatizar os concursos docente, a lei instituiu um curso para professores ingressantes "ao magistério paulista, como parte integrante do período probatório, com carga horária de, no mínimo, 360 horas, na forma a ser disciplinada em resolução do Secretário da Educação" (São Paulo, 2013, p. 1).

A expectativa era que esse curso potencializasse a ação educadora dos professores da Seduc/SP com estudos referentes ao seu campo de atuação, conforme a resolução SE 52, de 14/08/2013. Por essa razão, a referida resolução definiu

os perfis, competências e habilidades requeridos dos Profissionais da Educação da rede estadual de ensino, os referenciais bibliográficos e de legislação, que fundamentam e orientam a organização de exames, concursos e processos seletivos. (São Paulo, 2013, p. 1)

O curso para professores ingressantes da Seduc/SP faz parte das políticas de formação continuada de professores, assim como de indução profissional dessa rede de ensino (Mirissola, 2012; Constantin Junior, 2017). Esse curso, desde sua criação, tem contribuído significativamente para a inserção dos professores iniciantes na Seduc/SP (Silva, 2021).

Essa análise está pautada no entendimento de que a entrada numa carreira não é uma tarefa fácil, ao contrário, é um momento bastante complexo na vida de qualquer um de nós. $O$ ingresso na carreira docente vai nesse mesmo caminho, pois esse processo é marcado pela ruptura de um ciclo e o início de outro. Essa ruptura ocorre em razão da transição do ser estudante para tornar-se professor (Marcelo Garcia, 2006; Vaillant, 2009; Marcelo Garcia, 2011) sendo que essa fase é, muitas vezes, "marcada por acontecimentos e sentimentos por vezes contraditórios" (Nascimento et al., 2019, p. 154).

O terceiro mandato do governador Geraldo José Rodrigues Alckmin Filho (20152018) não trouxe grandes novidades no que diz respeito à formação continuada docente. Foi dada a continuidade dos programas que vinham ocorrendo até então. Ao analisarmos os relatórios anuais da Efape constatamos que a centralidade das ações, nesse período, 
esteve no curso de Professores Ingressantes, notadamente, para PEB I. A última edição deste curso foi em 2018 pois, a partir de 2019, lamentavelmente, ele foi descontinuado.

É importante salientar ainda que durante os dois mandatos do governo de Geraldo Alckmin foram marcados pela oferta cursos de extensão e atualização docente com foco na implementação curricular. Para se ter uma ideia do quantitativo de professores atendidos, apenas no ano de 2018 foram desenvolvidas 53 ações de formação continuada, conforme é evidenciado no relatório anual da Efape que sintetizou essa informação da seguinte forma:

Estão previstos, para o ano vigente, cerca de 53 ações de formação continuada, distribuídas nas seguintes categorias: Extensão e atualização

(11 cursos), Extensão e atualização com parceiros (30 cursos), Ingressantes ( 3 cursos), Programas de Formação (9 cursos). (Efape, 2018, p. 86)

De fato, essas ações merecem destaque, mas são pontuais e não se configuram como um programa de desenvolvimento profissional docente, conforme a própria Efape vem defendendo atualmente. Além disso, boa parte delas é continuada ou não de acordo com a perspectiva do governo vigente. Um exemplo disso foi a descontinuidade do curso de Professores Ingressantes ocorrida logo no início da gestão de João Dória.

A partir de $1^{\circ}$ de janeiro de 2019 João Agripino da Costa Doria Júnior, mais conhecido como João Dória, assumiu o governo paulista e foi lançado o Plano estratégico 2019-2022: educação para o século XXI. Foi possível perceber que a intenção do governo era chamar a atenção da sociedade e dos servidores com esse plano quer seja por meio do evento que o lançou ou a necessidade de torna-lo visível a todo momento por meio da instituição de sua imagem nos planos de fundo dos computadores interligados à Seduc/SP.

Tanto o governador João Dória, quanto o secretário da Educação, Rossieli Soares, foram incisivos em suas mensagens acerca da centralidade desse plano que é melhoria da qualidade da educação. Nas palavras do governador João Dória

São Paulo precisa ser a principal referência de educação pública no nosso País, o Estado líder no Ideb. E deve estar entre os sistemas que mais avançam na aprendizagem em todo o mundo, garantindo a todos os estudantes excelência na aprendizagem e a conclusão de todas as etapas da educação básica na idade certa. (São Paulo, 2019, p. 2)

Observa-se que, para além de uma aprendizagem de excelência por parte dos estudantes e a conclusão de todas as etapas da educação básica na idade certa, São Paulo precisa estar em destaque, ser a principal referência em educação pública no país, assim como liderar no Ideb. Esse ponto de vista é reiterado nas palavras do secretário Rossieli e de seu adjunto Haroldo Rocha que vão além, pois São Paulo precisa ser uma referência mundial em educação:

Com foco, determinação, trabalho em equipe e parceria com a sociedade, vamos fazer de São Paulo referência de educação pública no Brasil e posicioná-lo entre as redes que mais avançam na aprendizagem no mundo, oferecendo uma educação de excelência e com equidade para todas as crianças, adolescentes e jovens. (São Paulo, 2019, p. 3)

\begin{tabular}{|l|l|l|l|l|r|} 
Regae: Rev. Gest. Aval. Educ. & Santa Maria & v. 10 & n. 19 & e67223, p. 1-16 & 2021 \\
\hline
\end{tabular}


Tomando-se como referência as manifestações do governador João Dória e dos secretários da Seduc/SP, assim como o fato de que o plano estratégico Educação para o século $X X I$ tem metas audaciosas, a expectativa era que houvesse previsão de ações mais focadas na formação de professores, pois comumente a melhoria da educação está articulada com o incremento da formação docente. Todavia, o plano se restringe a apontar três desafios que foram diagnosticados sendo que apenas um faz referência à formação continuada de professores:

i) a formação inicial carece de foco na prática didática e não prepara adequadamente para os desafios da escola pública; ii) a necessidade de avaliar os resultados das atuais práticas de formação continuada; iii) a importância de um levantamento regionalizado das capacidades e das competências dos profissionais da educação, que permita ações diferenciadas e customizadas. (São Paulo, 2019, 13)

O que se percebeu no primeiro ano do governo de João Dória foi que, assim como outros governantes, ele tem buscado imprimir uma política educacional que não difere do que vinha ocorrendo até então. Com relação à formação continuada de professores a centralidade desse governo está na oferta de cursos de curta duração focalizando o conjunto de projetos prioritários do plano estratégico 2019-2022, notadamente, o projeto Inova Educação. Esse projeto consiste na mudança da matriz curricular do ensino fundamental, $6^{\circ}$ ao $9^{\circ}$ ano, e do ensino médio por meio da introdução de novos componentes curriculares. Com essa inovação, a matriz curricular da Seduc/SP passou a contar com o acréscimo de cinco aulas semanais e a introdução das disciplinas intituladas Projeto de Vida, Tecnologia e Inovação e Eletivas.

Apesar do aumento no número de disciplinas, não houve uma mudança significativa no tempo de permanência do estudante na escola. De modo mais efetivo a Seduc/SP reduziu o tempo das aulas de 50 para 45 minutos, ampliando o horário de permanência dos estudantes nas escolas em apenas 15 minutos diários. Noutras palavras, com a mudança os estudantes passaram a ter sete aulas por dia totalizando cinco horas e quinze minutos (São Paulo, 2019).

Em face ao exposto, no ano de 2019, foram ofertados três cursos que, no seu conjunto, certificaram 313.785 professores: Formação aprofundada: eletivas (104.790), Formação aprofundada: tecnologia e inovação (99.064) e Formação aprofundada: projeto de vida (109.931) (Efape, 2019).

Embora esses cursos se configurem como projetos de formação continuada de professores, são ações pontuais focalizando a implantação do Inova Educação e não o desenvolvimento profissional docente. Além disso, em 2019, houve, também um conjunto de outras ações formativas destinadas aos professores, mas em número bem menor quando comparada ao projeto Inova Educação. Essas ações foram realizadas por outras coordenadorias da Seduc/SP, por universidades, por entidades de classe ou por instituições parceiras com a autorização e homologação da Efape (Efape, 2019). 
No ano de 2020, em razão da pandemia, as ações de formação continuada inerentes ao plano estratégico 2019-2022 ficaram em segundo plano. Nesse ano, o foco da Efape foi a oferta do ensino remoto por meio do Centro de Mídias de São Paulo e, com isso, foram desenvolvidas inúmeras ações em caráter emergencial com vistas à qualificação dos professores para ministrar aulas remotamente.

\section{Considerações finais}

A Seduc/SP, por ser uma das maiores redes públicas de ensino do mundo tem uma responsabilidade muito grande quando o assunto é formação continuada, quer seja para professores ou para os profissionais da educação em termos mais abrangentes. Constatamos que a Efape tem sido a responsável pela formação continuada de professores dessa rede de ensino. Suas ações têm o foco na prática, incorporando novas tecnologias como ferramentas de formação continuada. Como seus cursos associam as modalidades presencial e o ensino a distância, por meio da transmissão de aulas e de conteúdos disponíveis em ambientes virtuais de aprendizagem, esse arranjo permite 0 atingimento de boa parte do quantitativo de professores e demais profissionais dessa rede de ensino.

A opção por esse modelo formativo faz sentido quando se observa que a Seduc/SP congrega mais de 234 mil servidores nos quadros do magistério, no quadro de apoio escolar e no quadro da Secretaria da Educação, presentes nos órgãos centrais e vinculados, em 91 diretorias de ensino e em cerca de 5.400 escolas. Mas a Efape conta, também com parcerias de universidades, entidades de classe e organizações nãogovernamentais para o desenvolvimento de projetos de formação continuada de professores.

Em geral, são feitos diagnósticos demonstrando problemas na formação inicial de professores e a necessidade de implementar programas de formação continuada, mas 0 que se observa é que as metas dos programas, em geral, focalizam a melhoria da qualidade da educação por meio de ações estratégicas que pouco contribuem para o desenvolvimento dos professores. Desse modo, são desenvolvidos cursos de curta duração focando determinado projeto que se constituem muito em mais em ações pontuais, para fins de certificação do que em programas e políticas de formação continuada de professores.

Não obstante, de um jeito ou de outro esses cursos favorecem os professores na implementação do currículo paulista e, de alguma forma, beneficiam a aprendizagem estudantil.

\section{Referências}

ADRIÃO, Teresa. Educação e produtividade: a reforma do ensino paulista e a desobrigação do Estado. São Paulo: Xamã, 2006.

ANDRÉ, Marli Eliza Dalmazo Afonso (org.). Formação de professores no Brasil (19901998). Brasília: MEC/Inep/Comped, 2002.

CONSTANTIN JUNIOR, José Carlos. Professores iniciantes do estado de São Paulo: a proposta de formação de ingressantes da SEE/SP 2017. Araraquara: Unesp, 2017. $162 f$. 
Dissertação (Mestrado em Educação). Faculdade de Ciências e Letras, campus de Araraquara.

DOURADO, Luiz Fernandes. Reforma do estado e as políticas para a educação superior no brasil nos anos 90. Educação e Sociedade, Campinas, v. 23, n. 80, 2002, p. 234-252.

DURAN, Marília Claret Geraes; ALVES, Maria Leila; PALMA FILHO, João Cardoso. Vinte anos da política do ciclo básico na rede estadual paulista. Cadernos de Pesquisa, São Paulo, v. 35, n. 124, 2005, p. 83-112.

EFAPE. Relatório 2011. Disponível em: https://efape.educacao.sp.gov.br/wpcontent/uploads/2021/03/relatorio2011.pdf Acesso em: 24 jul. 2021.

EFAPE. Relatório 2018. Disponível em: https://efape.educacao.sp.gov.br/wpcontent/uploads/2021/03/relatorio2018.pdf. Acesso em: 24 jul. 2021.

EFAPE. Relatório 2019. Disponível em: http://escoladeformacao.sp.gov.br/portais/Portals/84/docs/Relat\%C3\%B3rios\%20Anuais/R elatorio_2019.pdf. Acesso em: 8 ago. 2021.

FUSARI, José Cerchi. A educação do educador em serviço: o treinamento de professores em questão. São Paulo: PUCSP, 1988. 250f. Dissertação (Mestrado em Educação). Pontifícia Universidade Católica.

GATTI, Bernadete A. Análise das políticas públicas para formação continuada no Brasil, na última década. Revista Brasileira de Educação, Rio de Janeiro, v. 13, n. 37, 2008, p. 57-70.

GATTI, Bernadete A.; SÁ BARRETTO, Elba Siqueira de; ANDRÉ, Marli Eliza Dalmazo Afonso de; ALMEIDA, Patrícia Cristina Albieri de. Professores do Brasil: novos cenários de formação. Brasília: Unesco, 2019.

IMBERNÓN, Francisco. Formação docente e profissional: formar-se para a mudança e incerteza. São Paulo: Cortez, 2010.

IMBERNÓN, Francisco. Formação permanente do professor: novas tendências. São Paulo: Cortez, 2009.

KRAMER, Sônia. Melhoria da qualidade do ensino: o desafio da formação em serviço. Revista Brasileira de Estudos Pedagógicos, Brasília, v. 70. n. 165, 1989, p. 189-207.

KRASILCHIK, Myriam; NICOLAU, Marieta Lucia Machado; CURY, Maria Catarina. O Programa de Educação Continuada (PEC) na avaliação de seus alunos. Ciênc. Educ. (Bauru), Bauru, v. 14, n. 1, 2008, p. 169-180.

LIPPI, Bruno Gonçalves; NEIRA, Marcos Garcia. A formação de professores na rede estadual paulista entre 1983 e 2006: uma análise crítica. Educação: teoria e prática, Rio Claro, v. 23, n. 43, 2013, p. 76-92.

MARCELO GARCIA, Carlos. Políticas de inserción a la docencia: de eslabón perdido a puente para el desarrollo profesional docente. Preal: GTD, 2006.

MARCELO GARCIA, Carlos. Políticas de inserción en la docencia: de eslabón perdido a puente para el desarrollo profesional docente. Santiago: Preal, 2011.

MIRISOLA, Cristiane Dias. Inserção profissional docente no Estado de São Paulo: a escola de formação e o curso para professores ingressantes da SEE/SP. São Paulo: PUCSP, 2012. 220f. Dissertação (Mestrado em Educação). Pontifícia Universidade Católica de São Paulo. 
NASCIMENTO, Maria das Graças; FLORES, Maria José Batista Pinto; XAVIER, Daianne Bastos. Indução profissional docente: desafios e tensões no contexto de uma política pública. Currículo sem Fronteiras, s/l, v. 19, n. 1, 2019, p. 151-166.

MONTEIRO, Ângela Maria Arantes; ALVES, Jurema Silvia de Souza; TOLEDO, Maria Helena Campos Moura de; BRISOLA, Elisa Maria Andrade; CASTRO, Maria Aparecida Campos Diniz de. Formação de formadores: o dilema entre o papel executor e propositor no cotidiano da supervisão de ensino. Revista Acadêmica Magistério, Duque de Caxias, v. 2, n. 10, 2014, p. 122-137.

PALMA FILHO, João Cardoso. Reorganização do ensino fundamental na rede estadual de ensino paulista: memórias. In: PALMA FILHO, João Cardoso; ALVES, Maria Leila; DURAN, Marília Claret. Ciclo básico em São Paulo: memórias da educação nos anos 1980. São Paulo: Xamã, 2003, p. 17-57.

RODRIGUES, César Augusto. O programa Educação: compromisso de São Paulo e o novo modelo de escola de tempo integral: crítica à incorporação dos valores da lógica empresarial na educação escolar pública. Rev. HISTEDBR On-line, Campinas, v. 20, 2020, p. 1-23.

SÃO PAULO. Projeto básico teia do saber 2007. Disponível em http://cenp.edunet.sp.gov.br/forcont2007/arquivos/Projeto\%20Basico_nova_versao.pdf.

Acesso em: 15 ago. 2020.

SÃO PAULO. Decreto n. 55.650, de 29 de março de 2010: institui, no âmbito da Escola de Formação e Aperfeiçoamento dos Professores do Estado de São Paulo, da Secretaria da Educação, o Programa Rede São Paulo de Formação Docente - Redefor - e dá providências correlatas. Disponível em: https://www.al.sp.gov.br/repositorio/legislacao/decreto/2010/decreto-5565029.03.2010.html. Acesso em: 8 out. 2020.

SÃO PAULO. Resolução SE n. 22, de 18 de abril de 2013: institui o Programa Melhor Gestão, Melhor Ensino no âmbito da Secretaria da Educação. Disponível em: http://www.escoladeformacao.sp.gov.br/portais/Portals/131/Resolu\%C3\%A7\%C3\%A30\%2 0SE-22\%20de\%2018-4-2013\%20Programa\%20Melhor\%20Gest\%C3\%A3o.pdf. Acesso em: 8 out. 2020.

SÃO PAULO. Resolução SE 52, de 14 de agosto de 2013: dispõe sobre os perfis, competências e habilidades requeridos dos profissionais da educação da rede estadual de ensino, os referenciais bibliográficos e de legislação, que fundamentam e orientam a organização de exames, concursos e processos seletivos, e dá providências correlatas. Disponível em: http://www.educacao.sp.gov.br/cgrh/wpcontent/uploads/2014/06/RESOLU\%C3\%87\%C3\%83O-SE-52-de-14-8-2013-PERFISPARA-CONCURSO.pdf. Acesso em: 07 set. 2020.

SÃO PAULO. Resolução Seduc/SP n. 4, de 11 de janeiro de 2021: institui o Projeto de Assistência ao Currículo (PAC) e dá providências correlatas. Disponível em: https://deguaratingueta.educacao.sp.gov.br/resolucao-Seduc/SP-4-de-11-1-2021-instituio-projeto-de-assistencia-ao-curriculo-pac-e-da-providencias-correlatas/. Acesso em: 24 de jul. 2021.

SÃO PAULO. Decreto n. 57.571, de 2 de dezembro de 2011: institui, junto à Secretaria da Educação, o Programa Educação - Compromisso de São Paulo e dá providências correlatas. em: https://www.al.sp.gov.br/repositorio/legislacao/decreto/2011/decreto-5757102.12.2011.html. Acesso em: 24 jul. 2021. 
SÃO PAULO. Inova educação. São Paulo: Efape, 2019b. Disponível em: https://inova.educacao.sp.gov.br/ Acesso em 8 de ago. 2021.

SÃO PAULO. Plano estratégico 2019-2022: educação para o século XXI. São Paulo: Seduc/SP, 2019. Disponível em: https://www.educacao.sp.gov.br/wpcontent/uploads/2019/07/Plano-estrategico2019-2022_final-5-min.pdf. Acesso em: 8 ago. 2021.

SILVA, Sarah Maria de Freitas Machado. As bases teóricas e políticas na formação continuada dos professores da rede estadual de ensino do Estado de São Paulo: a escola de formação e aperfeiçoamento em análise. Campinas: Unicamp, 2015. 327f. Tese (doutorado em educação) Universidade Estadual de Campinas.

SILVA, André dos Anjos C. Formação continuada e indução profissional docente: o curso de professores ingressantes da rede estadual paulista. São Caetano do Sul: USCS, 2021. 178f. Dissertação (mestrado em Educação). Universidade Municipal de São Caetano do Sul.

UTSUMI, Miriam Cardoso. Escola-padrão: avanço na melhoria do ensino? Campinas: Unicamp, 1995. 193f. Dissertação (Mestrado em Educação). Universidade de Campinas.

VAILLANT, Denise. Políticas de inserción a la docencia en américa latina: la deuda pendiente. Profesorado: Revista de Currículum y Formación de Profesorado, Granada, v. 13, n. 1, 2009, p. 27- 41.

VIEIRA, Jarbas Santos. Política educacional, currículo e controle disciplinar: implicações sobre o trabalho docente e a identidade do professorado. Currículo sem Fronteiras, s/l, v. 2, n. 2, 2002, p. 111-136.

Nonato Assis de Miranda é professor na Universidade Municipal de São Caetano do Sul.

Orcid: https://orcid.org/0000-0001-6592-3381.

Endereço: Rua João Moura, 2370/62 - 05412-004 - São Paulo - SP - Brasil.

E-mail: mirandanonato@uol.com.br.

André dos Anjos Cangueiro Silva é professor na Universidade Paulista.

Orcid: https://orcid.org/0000-0001-7480-4982.

Endereço: Rua João Moura, 2370/62 - 05412-004 - São Paulo - SP - Brasil.

E-mail: andre anjos@yahoo.com.br.

Ana Silvia Moço Aparício é professora na Universidade Municipal de São Caetano do Sul.

Orcid: https://orcid.org/0000-0001-6725-5372.

Endereço: Rua Conceição, 321 - 09530-060 - São Caetano do Sul - SP - Brasil.

E-mail: anaparicio@uol.com.br. 
Leliane Aparecida Gliosce Moreira é professora na Universidade Paulista.

Orcid: https://orcid.org/0000-0002-1919-1623.

Endereço: Rua Dr. Bacelar, 1212 - 04026-002 - São Paulo - SP - Brasil.

E-mail: leliane.moreira@docente.unip.br.

Critérios de autoria: os autores conceberam a ideia. Nonato e André fizeram o levantamento documental. Todos os autores analisaram os dados e colaboraram com escrita do texto. Ana fez a revisão final do manuscrito.

Recebido em 15 de agosto de 2021.

Aceito em 30 de outubro de 2021.

(c) $(i)(3)$ 